\title{
The influence of the dye adsorption time on the DSSC performance
}

\author{
Ewelina $\mathrm{Krawczak}^{1, *}$, and Agata Zdyb ${ }^{1}$ \\ ${ }^{1}$ Faculty of Environmental Engineering, Lublin University of Technology, ul. Nadbystrzycka 38, \\ 20-618 Lublin, Poland
}

\begin{abstract}
Dye-sensitized solar cells (DSSC) of third generation photovoltaic technology, are nowadays one of the most investigated due to possibility to apply ecological and natural materials (dyes) such as alizarin. This paper reports the influence of electrode immersion time on alizarinbased dye-sensitized solar cells performance. The absorption spectra of alizarin dye were measured in the range of $300-800 \mathrm{~nm}$. Fully structured dye-sensitized cells of working area equal to $0.8 \mathrm{~cm}^{2}$ have been fabricated in the sandwich way using four different immersion times of the $\mathrm{TiO}_{2}$ electrodes: 10', 40', 1 h, 24 h. The high-performance EL- HPE electrolyte was instilled into the space between electrodes. Current-voltage (I-V) dark and illuminated characteristics have been measured using solar light simulator. Solar cells characterization was carried out under standard test conditions. The solar irradiance was set at $100 \mathrm{~mW} / \mathrm{cm}^{2}$ and temperature of the module was maintained at $25^{\circ} \mathrm{C}$. Characteristic parameters of the fabricated cells were determined on the basis of measured I-V curves. Series resistances were extracted from I-V characteristics at an open circuit voltage using first order derivatives. It was found that 60 minutes of electrode immersion in dye solution is sufficient to obtain appropriate stage of the dye adsorption.
\end{abstract}

\section{Introduction}

In recent years, the intensive development of renewable energy sources have been noticed all over the world. It is motivated by depletion of fossil fuel resources, increasing of their prices and still growing global energy demands. It is estimated that taking into account the current demand for electricity, the reserves of fossil fuels will last only 40, 60 and 200 years for oil, natural gas, and coal respectively [1]. The climatic consequences of fossil fuels combustion are not without significance because of greenhouse gases emission to the atmosphere. Preservation of the environment during the process of energy production is crucial. According to Directive 2009/28/EC of the European Parliament and of the Council of 23 April 2009, the target for European countries to be achieved by the end of 2030 is $32 \%$ of EU's final energy consumption [2]. The above mentioned factors are the most significant reasons to explore alternative energy sources, especially renewable ones. Many research

\footnotetext{
* Corresponding author: e.krawczak@pollub.pl
} 
groups focus on solar energy because it is considered as environmentally friendly source with huge potential, which is able to meet the current and subsequent generations energy requirements. Direct conversion of the energy from the Sun into electricity can be achieved by photovoltaic (PV) devices. Photovoltaic cells are divided into three categories called generations, which are related directly to different materials and have various photoelectric conversion efficiencies. The first generation of solar cells is based on crystalline silicon material. It is relatively expensive which causes high cost of producing. However, silicon wafer-based solar cells are the most effective ones. Yoshikawa et al. [3] obtained highest noticed silicon cell efficiency of $26.7 \%$. The second generation of solar cells is characterized by less material usage [4], which allows to produce cells of high efficiency. Materials that are typically used in thin film solar cells are cadmium sulfide (CdS), cadmium telluride (CdTe) [5], amorphous silicon (a-Si) [6] and copper-indium-diselenide/copper-indiumgallium-diselenide (CIS/CIGS) [7, 8]. Recent highest noticed efficiency of the laboratory CIGS cell equals $22.4 \%$ and is close to the efficiency of the silicon devices, which makes the possibility of replacing Si crystalline solar cells with the CIGS [9]. The third generation of photovoltaic cells is a promising alternative to conventional cells based on the $p-n$ junction. Dye-sensitized solar cell (DSSC) technology can be considered as an economical substitute with relatively high conversion efficiency. Typical DSSC device consists of photoanode, counter electrode with platinum catalyst layer and electrolyte, made of mesoporous semiconductor layer and dye sensitizer. Both electrodes are based on transparent conductive oxide materials (TCOs), especially on indium tin oxide (ITO) [10] or fluorine-doped tin oxide (FTO) [11]. Interesting alternative to ITO is also $\mathrm{ZnO}$ doped with trivalent elements such as $\mathrm{Al}[12-15], \mathrm{Ga}[12,16]$ or $\mathrm{B}$ [17] which is a material that can even improve its electrical properties, like conductivity, during annealing process required in DSSC.

The dye sensitizer is considered as a crucial component that strongly affects the performance of the working cell. The phenomenon which plays an important role in the performance of dye-sensitized solar cells is electron transfer from the excited state of the dye molecule to the conduction band of titanium dioxide nanoparticle [18-20]. The course of the light-induced transfer of electrons from the sensitizer to a semiconductor depends mainly on the type of the dye i.e. the shape of its molecule and energy levels positions. The best performing dyes are made of Ru complexes (e.g. N3, N719, and black dyes) [21, 22]. Mathew et al. [23] obtained the record efficiency of $13 \%$ for Ru-based DSSC. However, the high production cost, complicated synthesis and harmful effect on the environment, made the researchers search alternative to Ru-based compounds [24]. Variety of natural resources, which are environmentally friendly, can be used as a origin of dyes sensitizers, such as plants, flowers, fruits $[25,26]$. Nevertheless, the efficiency of natural dye-based cells should be improved for the extensive application of DSSC. Various groups [27-29] have been working on implementing natural dyes, such as alizarin, quercetin or luteolin. Alizarin is a red dye extracted from the root of Rubia tinctorum. However, this dye can be also obtained by laboratory methods from anthraquinone. Alizarin is characterized by rapid injection photoexcited electrons into the semiconductor conduction band.

The amount of the adsorbed dye also influences the efficiency of the DSSC device and can be adjusted by the change of the concentration of the dye solution or the time of the photoelectrode dipping in the solution. This paper presents the time of electrode immersion influence on alizarin-based dye-sensitized solar cells performance. DSSC devices were prepared by the use of prefabricated components and dyed with alizarin dye.

\section{Materials and methods}

In this research, the dye-sensitized solar cells were prepared with the use of alizarin dye (Fig. 1) purchased by Sigma-Aldrich. Initially, the $2 \mathrm{mM}$ solution of alizarin dye was 
prepared in ethanol (99.8\%). The absorption spectra were measured in the range of 300-800 nm by Shimadzu UV-vis spectrophotometer. Addition of dye resulted in colour progress, from transparent to dark purple. In order to improve solubility, the dye solution was ultrasonically mixed for 10 minutes. Afterwards, the photoanodes coated with $\mathrm{TiO}_{2}$ (Greatcell Solar) were placed in a dye solution. The immersion time was different for each series of experiments: 10 minutes, 40 minutes, 1 hour and 24 hours. The container of dye solution was left without access to light, owing to the fact that particles are extremely photosensitive, especially in a solution form. After that, the electrodes were taken out and rinsed with the ethanol in order to eliminate excessive dye molecules. The photoelectrodes were dried for 30 minutes in the ambient environment and then were immediately used in the DSSC structures. DSSCs were assembled in the sandwich way. Counter electrode with a platinum catalyst layer (Greatcell Solar) was used to face the titania surface deposited onto photoanode. DSSC devices were sealed by a thermoplastic sealant (Dye Sol). The whole assembly was heated in high-temperature titan hotplate. The heat was supplied to the structure from the top and the bottom. Heating was carried out in three steps. Firstly, the structure was heated up to $90^{\circ} \mathrm{C}$ for 2 minutes, secondly, the temperature was raised to $110^{\circ} \mathrm{C}$ and held by 2 minutes. Finally, the temperature of $115^{\circ} \mathrm{C}$ was set and kept by the time of 2 minutes. After this procedure, the DSSC assemblies were left to cool down. Then, the highperformance EL- HPE electrolyte by Greatcell Solar was instilled into the space between electrodes through a drilled hole in the counter electrode. The working area of the DSSC structure was fixed as $0.8 \mathrm{~cm}^{2}$. Then, the contacts were made by the use of silver tape. A scheme of the dye-sensitized solar cell is presented in Fig. 2.

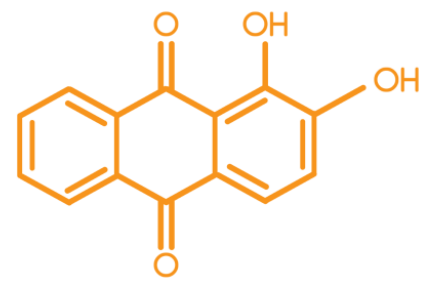

Fig. 1. The molecular structure of alizarin dye.

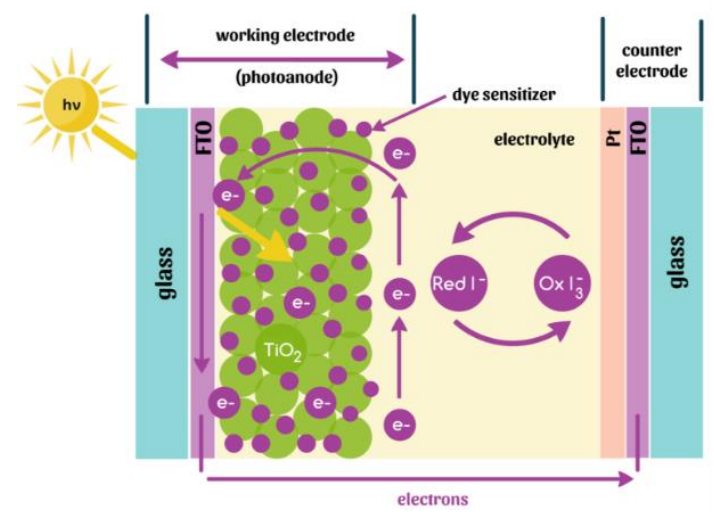

Fig. 2. A scheme of the dye-sensitized solar cell.

The current-voltage characteristics were immediately measured in dark and in illuminated conditions by SUN 3000 solar light simulator of Abet Technologies, class AAA. The simulator is equipped with Xe lamp $(450 \mathrm{~W})$. The solar irradiation was set at $100 \mathrm{~mW} / \mathrm{cm}^{2}$. The data were collected by a Keithley Instruments, type 2440, electrometer with integrated power supply. The ReRa Tracer software was used to measure and calculate various performance parameters.

\section{Results and discussion}

Initially, alizarin dye was characterized in order to obtain absorption spectrum by the use of spectrophotometer (Fig. 3). The dye exhibits the wide absorption spectrum in the range of 400 to $600 \mathrm{~nm}$ (in the visible range) with a major peak at $432.5 \mathrm{~nm}$. It can be seen that 
characterized dye has a strong absorption in the violet region. On the basis of the absorption data, the value of optical band gap, HOMO-LUMO distance was estimated to be equal to $2.13 \mathrm{eV}$.

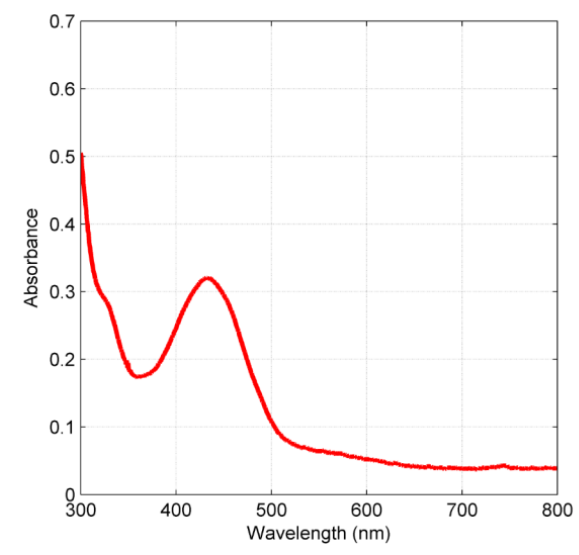

Fig. 3. UV-vis absorption spectrum of alizarin dye.

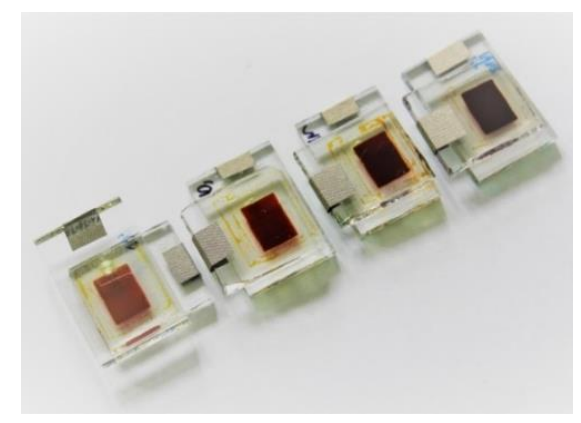

Fig. 4. Alizarin-based dye-sensitized solar cells for different immersion times, from left: $10 \mathrm{~min}$, $40 \mathrm{~min}, 60 \mathrm{~min}, 24 \mathrm{~h}$.

The dye sensitized solar cells were prepared in the way described in Experimental section. The obtained cells sensitized with alizarin dye as a sensitizer are shown in Fig.4. The change in colour from orangish to dark purple was noticed for different times of photoanode immersion in dye solution ( $10 \mathrm{~min}, 40 \mathrm{~min}, 60 \mathrm{~min}$ and $24 \mathrm{~h}$ ). As can be seen in Figure 4, the time of the immersion has a strong influence on the colour of the semiconductor layer. Electrodes immersed for short time, such as 10 minutes and 40 minutes are characterized with a brighter colour (near to orange) while longer immersion times results in the dark purple colour of the electrodes, which means that the adsorption process proceeds in time.

The I-V characteristics of the cells based on a $\mathrm{TiO}_{2}$ substrate using alizarin as a sensitizer were measured under the standard light intensity of $100 \mathrm{~mW} / \mathrm{cm}^{2}$ by a solar simulator. On the basis of obtained parameters, i.e. short circuit current $\left(I_{s c}\right)$, short-circuit current density $\left(J_{s c}\right)$, open circuit voltage $\left(V_{o c}\right)$, maximum power point current $\left(I_{M P P}\right)$ and maximum power point voltage $\left(V_{M P P}\right)$, the value of fill factor was calculated. The fill factor is a parameter which defines the quality of the solar cell and can be defined as the ratio of the maximum power to the short-circuit current density and open circuit voltage values. The more the characteristic resembled a rectangle, the higher value is reached by fill factor. The fill factor value can be calculated on the basis of equation (1) [26].

$$
F F=\frac{V_{M P P} \cdot I_{M P P}}{V_{o c} \cdot I_{S C}}
$$

Fill factor is used to assess the power loss of electric current resulting from the internal resistance of the cell, the losses caused by recombination and other losses. 
a)
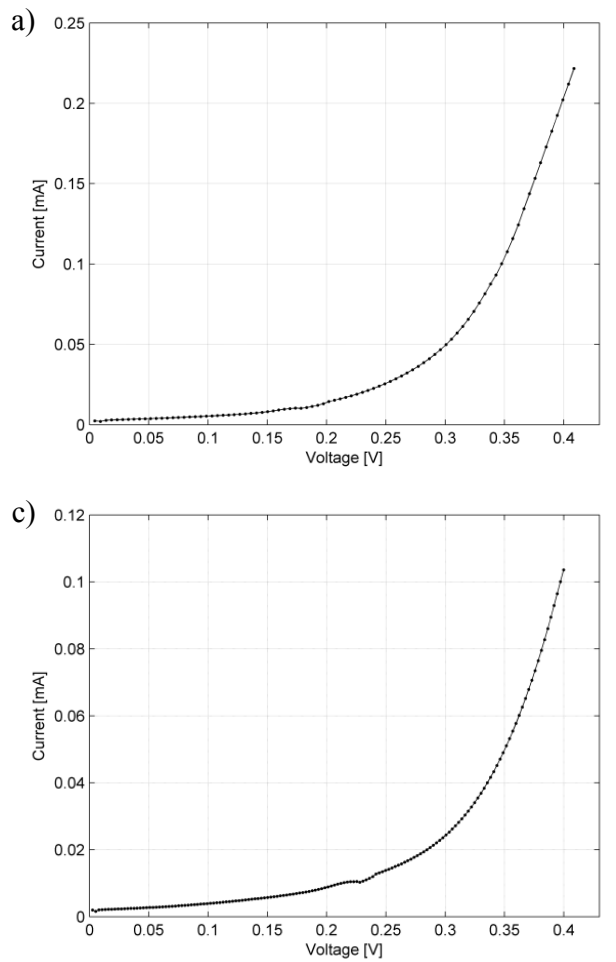

b)

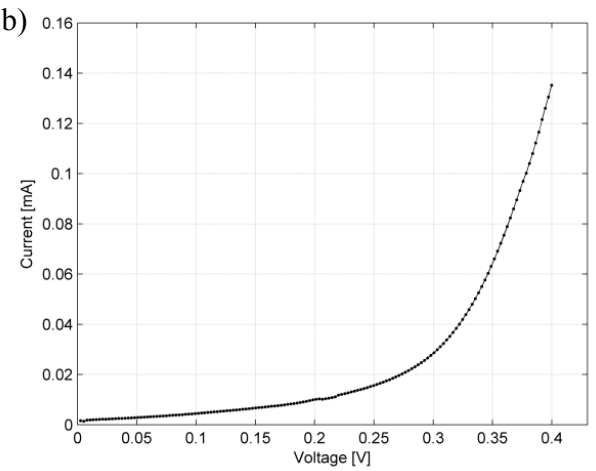

d)

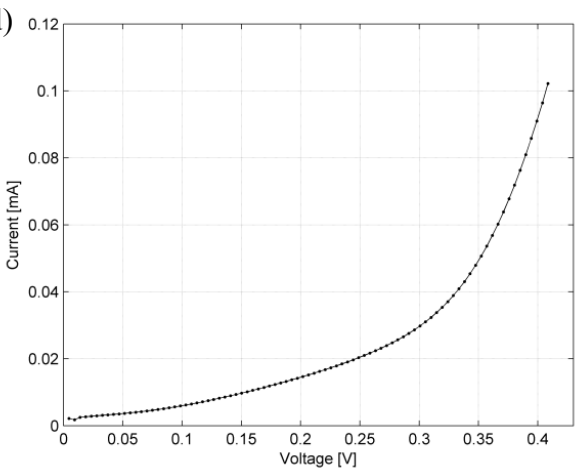

Fig. 5. I-V dark characteristics for alizarin dye-based DSSC for different immersion time: a) $10 \mathrm{~min}$, b) $40 \mathrm{~min}$, c) $60 \mathrm{~min}$, d) $24 \mathrm{~h}$.

Dark characteristics of the prepared dye-sensitized cells are shown in Fig. 5. Their shape is typical for semiconductor diode. The comparison with the I-V curves obtained for illuminated devices, which are presented in Fig. 6., depicts that introducing the light results in the less bent shape of the curves. Thus the role of series resistance is visible. The values of the series resistance were obtained as a reverse shape of the straight line fitted near $I_{s c}=0$. Series resistance, $R s$, is a parameter that represents the series resistive losses which occur inside the solar cell during the current flow through the solar cell volume. Current generated inside the solar cell travels through resistive semiconductor layer of $\mathrm{FTO} / \mathrm{TiO}_{2}$. There are also resistances on TCO interconnections and cell metallization. Although the open circuit voltage is independent of the series resistance $R s$, the short circuit current and especially the fill factor strongly depends on $R s$ and decreases with the increase of series resistance of the cell. The value for $R s$ can be calculated from the current-voltage (I-V) curve of the solar cell [30]. The slope at open circuit voltage $V_{o c}$ provides the negative inverse value for $R_{s, 0}$ according to the formula (2).

$$
\left.\frac{d I}{d V}\right|_{V=V_{o c}}=-\frac{1}{R_{S, 0}}
$$

Using the extracted value of $R_{s, 0}$ from I-V curve the series resistance can be calculated on the basis of the formula (3).

$$
R_{s}=R_{s, 0}-\frac{n V_{t h}}{I_{0}} e^{\frac{-V_{o c}}{n V_{t h}}}
$$


where $n=1, V_{\text {th }}$ is the thermal voltage $\left(k T / q, k=1.381 \cdot 10^{-23} \mathrm{~J} / \mathrm{K}, q=1.602 \cdot 10^{-19} \mathrm{C}\right.$ and $T=297 \mathrm{~K}$ ). Reverse saturation current, $I_{0}$ can be calculated by equation (4).

$$
I_{0}=I_{s c} \cdot e^{-\frac{V_{o c}}{n V_{t h}}}
$$

On the basis on the above-mentioned method, the $R s$ values for immersion times equal to $10 \mathrm{~min}, 40 \mathrm{~min}, 60 \mathrm{~min}$, and $24 \mathrm{~h}$ were estimated to be $2.11 \mathrm{k} \Omega, 2.27 \mathrm{k} \Omega, 2.57 \mathrm{k} \Omega$, and $2.74 \mathrm{k} \Omega$ respectively. Figure 6 shows the current-voltage characteristics for the devices with the various immersion times. Usage of the electrode immersed for 10 minutes leads to the worse properties of DSSC devices. Adsorption of the dye molecules onto the $\mathrm{TiO}_{2}$ layer, in such a short time, was insufficient which resulted in low parameters values.

a)

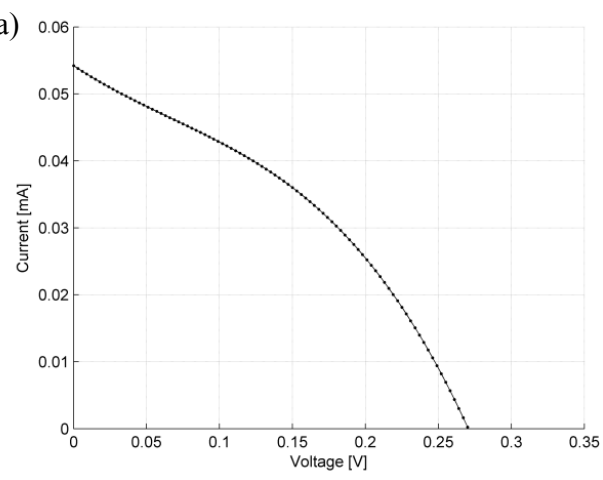

c)

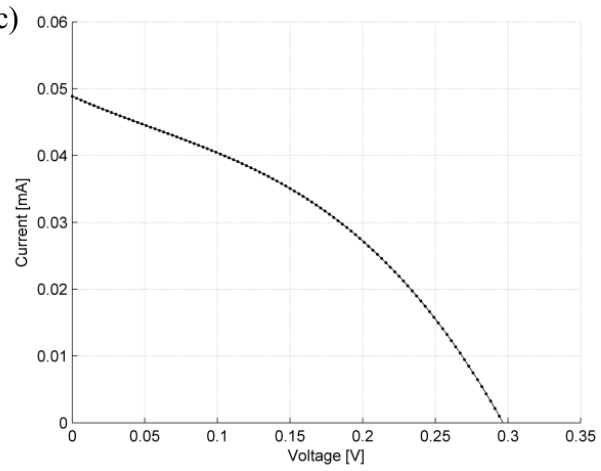

b)

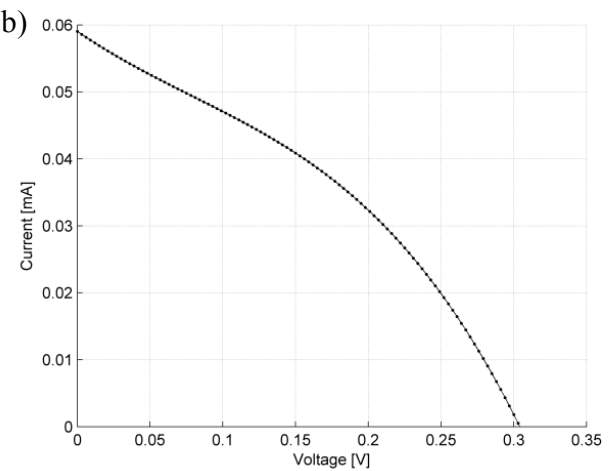

d)

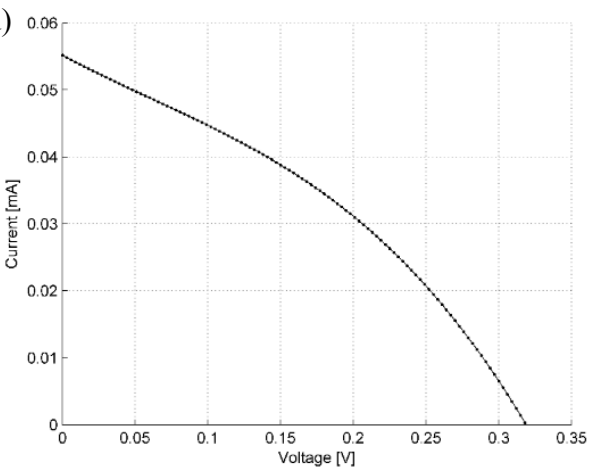

Fig. 6. I-V characteristics for alizarin dye-based DSSC for different immersion time: a) $10 \mathrm{~min}$, b) $40 \mathrm{~min}, \mathrm{c)} 60 \mathrm{~min}, \mathrm{~d}) 24 \mathrm{~h}$.

A comparison of various performance parameters for different immersion times are presented in Table 1. As can be seen, the highest short-circuit current density value was found for an electrode submerged for 10 minutes. Increasing of the immersion time led to decreasing $J_{s c}$ value in the range of $0.095-0.058 \mathrm{~mA} / \mathrm{cm}^{2}$. Open circuit voltage increases for longer absorption times and its value was found to be the best for cell 4 and equal to $318.82 \mathrm{mV}$, whilst the lowest was obtained for cell $1(270.52 \mathrm{mV})$. The open circuit voltage is the parameter depending on the energy of LUMO level of the dye and its distance from to the conduction band of a semiconductor used in the device. The main limitation of $V_{o c}$ value is the recombination of electrons present in conduction band with the ions from the electrolyte. Comparing all the parameters, it can be summarized that 60 minutes immersed electrode-based cells present the best performance parameters, especially fill factor, with 24 times shorter time, than cell 4. 
Table 1. Performance parameters for different immersion times.

\begin{tabular}{|c|c|c|c|c|c|c|c|c|c|}
\hline \multirow{2}{*}{$\mathbf{N}^{\mathbf{0}}$ cell } & \multirow{2}{*}{$\begin{array}{c}\text { Immersion } \\
\text { time }\end{array}$} & $\boldsymbol{J}_{\boldsymbol{s c}}$ & $\boldsymbol{I}_{\boldsymbol{s c}}$ & $\boldsymbol{V}_{\boldsymbol{c}}$ & $\boldsymbol{I}_{\boldsymbol{m} p \boldsymbol{p}}$ & $\boldsymbol{V}_{\boldsymbol{m} p \boldsymbol{p}}$ & $\boldsymbol{P}_{\boldsymbol{m} p \boldsymbol{p}}$ & $\boldsymbol{F F}$ & $\boldsymbol{R}_{\boldsymbol{S}}$ \\
\cline { 3 - 11 } & {$\left[\mathrm{mA} / \mathrm{cm}^{2}\right]$} & {$[\mathrm{mA}]$} & {$[\mathrm{mV}]$} & {$[\mathrm{mA}]$} & {$[\mathrm{mV}]$} & {$[\mathrm{mW}]$} & {$[\%]$} & {$[\mathrm{k} \Omega]$} \\
\hline cell 1 & $10 \mathrm{~min}$ & 0.095 & 0.054 & 270.52 & 0.031 & 158.34 & 0.005 & 33.47 & 2.11 \\
\hline cell 2 & $40 \mathrm{~min}$ & 0.075 & 0.060 & 304.19 & 0.034 & 189.21 & 0.006 & 35.82 & 2.27 \\
\hline cell 3 & $\mathbf{6 0} \mathbf{~ m i n}$ & $\mathbf{0 . 0 6 3}$ & $\mathbf{0 . 0 4 8}$ & $\mathbf{2 9 6 . 6 0}$ & $\mathbf{0 . 0 3 0}$ & $\mathbf{1 8 3 . 8 8}$ & $\mathbf{0 . 0 0 6}$ & $\mathbf{3 8 . 0 6}$ & $\mathbf{2 . 5 7}$ \\
\hline cell 4 & $24 \mathrm{~h}$ & 0.058 & 0.055 & 318.82 & 0.028 & 183.58 & 0.005 & 29.22 & 2.73 \\
\hline
\end{tabular}

The fill factor parameter was found to increase with increasing immersion time up to $60 \mathrm{~min}$. Further increase of the immersion time have not led to better performance of the device. What is more, the slightly worse value of fill factor has been noticed for the immersion time of $24 \mathrm{~h}$ (cell 4).

\section{Conclusion}

The influence of the immersion time of the photoelectrode in the dye solution on dye-sensitized solar cells performance was studied. DSSC devices were obtained on the basis of alizarin dye with various immersion time equal to $10 \mathrm{~min}, 40 \mathrm{~min}, 60 \mathrm{~min}$ and 24 hours. The performed investigation leads to the conclusion that alizarin dye is appropriate to be used as a sensitizer in dye-sensitized solar cells because it is characterized by a wide absorption spectrum in the visible range of 400 to $600 \mathrm{~nm}$, which can be compared with others dyes reported in the literature. The performance of obtained devices was studied by employ illuminated and dark current-voltage characteristics. It was found that the shape of dark I-V curves is typical for semiconductor diode. The influence of the series resistance on the illuminated characteristics is visible. $R s$ values have a strong influence on short circuit current values, which is very low. However, the cells were characterized by $V_{o c}$ values in the range from 270.52 to $318.82 \mathrm{mV}$, which are appropriate for dye-sensitized assemblies. The fill factor values changed in the range of $29.22 \%-38.06 \%$. The cell 3 characterized by 60 minutes of immersion time shows maximum FF value, while the lowest value was found for immersion time equals 24 hours. It can be summarised that DSSC structure immersed for 60 minutes reveals the best performance parameters and this time can be considered as optimal for alizarin dye. Further increasing of the immersion time does not lead to better parameters, fill factor especially. Further investigation is necessary in order to improve the values of all significant parameters of working dye-sensitized solar cells prepared by the use of natural dye, such as alizarin.

\section{References}

1. B. Li, L. Wang, B. Kang, P. Wang, Y. Qiu, Sol. Energ. Mat. Sol. C 90, 549-573 (2006)

2. Eurepean Commisssion Statement, http://europa.eu/rapid/press-release_STATEMENT18-4155_en.htm

3. K. Yoshikawa, H. Kawasaki, W. Yoshida, T. Irie, K. Konishi, K. Nakano, T. Uto, D. Adachi, M. Kanematsu, H. Uzu, K. Yamamoto, Nat. Energy 2, 17032 (2017) 
4. J. M. Olchowik, K. Cieslak, S. Gulkowski, A. Kaminski, A. Fave, 2010 35th IEEE Photovoltaic Specialists Conference, 003546-003548 (2010)

5. J. Sites, J. Pan, Thin Solid Films 515, (15), 6099-6102 (2007)

6. T. Matsui, H. Sai, A. Bidiville, H.-J. Hsu, K. Matsubara, Sol. Energy 170, 486-498 (2018)

7. V. Bermudez, Sol. Energy 175, 2-8 (2018)

8. S. Gulkowski, E. Krawczak, E3S Web of Conferences 19, 03006 (2017)

9. P. Jackson, R. Wuerz. D. Hariskos, E. Lotter, W. Witte, M. Powalla, Phys. Status Solidi RRL 10, 583-586 (2016)

10. A. S. Shikoh, Z. Ahmad, F. Touati, R. A. Shakoor, S. A. Al-Muhtaseb, Ceram. Int. 43, 10540-10545 (2017)

11. W. Li, F. Lv, T. Shu, X. Tan, L. Jiang, T. Xiao, P. Xiang, Mater. Lett. 243, 108-111 (2019)

12. K.- M. Kang, Y. Wang, M. Kim, H.-H. Park, Thin Solid Films 660, 913-919 (2018)

13. A. Zdyb, E. Krawczak, P. Lichograj, Opt. Appl. 46, 181-185 (2016)

14. E. Krawczak, A. Zdyb, S. Gulkowski, A. Fave, E. Fourmond, E3S Web of Conferences 22, 00090 (2017)

15. A. Zdyb, E. Krawczak, S. Gulkowski, Opto-Electron Rev. 26, 247-251 (2018)

16. C. Bhoomanee, S. Nilphai, S. Sutthana, P. Ruankham, S. Choopun, D. Wongratanaphisan, Integr Ferroelectr. 165, 121-130 (2015)

17. L.- H. Wong, Y.-S. Lai, Thin Solid Films 583, 205-211 (2015)

18. A. Zdyb, S. Krawczyk, Appl. Surf. Sci. 256, 4854-4858 (2010)

19. A. Zdyb, S. Krawczyk, Chem. Phys. 443, 61-66 (2014)

20. A. Zdyb, S. Krawczyk, Spectrochim. Acta A Mol. Biomol. Spectrosc. 157, 197-203 (2016)

21. A. S. Shikoh, Z. Ahmad, F. Touati, S. A. Al-Muhtaseb, Opt. Mater. 78, 201-2016 (2018)

22. P. Naik, I. M. Abdellah, M. Abdel-Shakour, R. Su, K. S. Keremane, A. El-Shafei, A. V. Adhikari, Sol. Energy 174, 999-1007 (2018)

23. S. Mathew, A. Yella, P. Gao, R. Humphry-Baker, B. F. E. Curchod, N. Ashari-Astani, I. Tavernelli, U. Rothlisberger, Md. K. Nazeeruddin, M. Grätzel, Nat. Chem. 6, 242-247 (2014)

24. D. Zhang, S. M. Lanier, J. A. Downing, J. L. Avent, J. Lum, J. L. McHale, J. Photoch. Photobio. A 195, 72-80 (2008)

25. H. Zhou, L. Wu, Y. Gao, T. Ma, J. Photoch. Photobio. A 219, 188-194 (2011)

26. W. A. Ayalew, D. W. Ayele, Journal of Science: Advanced Materials and Devices 1, 488-494 (2016)

27. R. Sánchez-de-Armas, M. A. San-Miguel, J. Oviedo, J. Fdez. Sanz, Comput. Theor. Chem. 975, 99-105 (2011)

28. S. Çakar, M. Özacar, J. Photoch. Photobio. A 346, 512-522 (2017)

29. S. Shalini, N. Prabavathy, R. Balasundaraprabhu, T. S. Kumar, D. Velauthapillai, P. Balraju, S. Prasanna, Optik 155, 334-343 (2018)

30. F. Ghani, G. Rosengarten, M. Duke, J. K. Carson, Renew. Energ. 72, 105-112 (2014) 